\title{
LETTER
}

\section{Subglottic secretion drainage in prevention of ventilator-associated pneumonia: mind the gap between studies and reality}

\author{
Thibault Loupec ${ }^{1,2^{*}}$, Franck Petitpas ${ }^{1,3}$, Pierre Kalfon ${ }^{4}$ and Olivier Mimoz ${ }^{1,2,3}$
}

Despite application of preventive measures in bundles, ventilator-associated pneumonia (VAP) remains the most common nosocomial infection, leading to increases in mechanical ventilation duration, ICU stay and healthcare costs [1]. Although two meta-analyses report a half reduction of VAP following use of endotracheal tubes (ETTs) with subglottic secretion drainage (SSD) [2], these devices are not widely employed in clinical practice.

Although ETTs with SSD are more expensive, Kelley demonstrates from statistical analyses that these devices could represent health savings [3]. Management of patients intubated before admission to ICU and requiring prolonged mechanical ventilation ( $\geq 72$ hours) is another concern. This large subgroup is usually excluded from studies evaluating ETTs with SSD even though they may benefit from these devices [4]. In the French IPREA multicenter prospective trial assessing discomforts perceived by 1,380 unselected patients admitted to 14 ICUs between March and November 2005, 869 (63\%) patients required intubation and mechanical ventilation. Of these, 541 (62\%) were intubated before ICU admission, representing 3,001 (50\%) of 5,971 days of mechanical ventilation [5]. This proportion is $48 \%$ when only patients requiring $72 \mathrm{~h}$ of mechanical ventilation or more are considered. In the IPREA 2 study, of 1,643 patients admitted to 17 French ICUs between March and November 2008 (personal unpublished data), 1,064 (64.8\%) were mechanically ventilated. Of the 7,857 days of mechanical ventilation, $54 \%$ occurred while the patients were intubated before ICU admission. This proportion is $45 \%$ in patients requiring at least 72 hours of mechanical ventilation.

\footnotetext{
* Correspondence: t.loupec@gmail.com

${ }^{1} \mathrm{CHU}$ de Poitiers, Service d'Anesthésie et de Réanimation, Poitiers 86000, France

${ }^{2}$ Université de Poitiers, Faculté de Médecine et Pharmacie, Poitiers 86000, France

Full list of author information is available at the end of the article
}

Using ETTs with SSD for all mechanically ventilated patients would lead to significant unjustified incremental costs and is unadvisable. Replacing standard ETTs by ETTs with SSD at ICU admission would increase the risk of microaspiration and is not advisable either. Identifying patients who are at risk to be mechanically ventilated for at least 72 hours at the time of intubation before ICU admission, or using convertible ETTs that feature a separate suction line allowing for subglottic secretion suctioning on demand are suggested solutions to reduce VAP.

In conclusion, the proportion of patients admitted to ICU yet intubated and requiring prolonged mechanical ventilation is high. Availability of ETTs with SSD before ICU admission for patients eligible for these devices or generalization of convertible ETTs allowing for subglottic secretion suctioning on demand might decrease VAP incidence without uselessly increasing healthcare costs.

\section{Abbreviations}

ETT: endotracheal tube; SSD: subglottic secretion drainage; VAP: ventilatorassociated pneumonia.

\section{Competing interests}

The authors declare that they have no competing interests.

\section{Author details}

${ }^{1} \mathrm{CHU}$ de Poitiers, Service d'Anesthésie et de Réanimation, Poitiers 86000, France. ${ }^{2}$ Université de Poitiers, Faculté de Médecine et Pharmacie, Poitiers 86000, France. ${ }^{3}$ INSERM U1070, Pharmacologie des Agents Anti-Infectieux, Poitiers 86000, France. ${ }^{4}$ Centre Hospitalier Louis Pasteur, Le Coudray 28630, France.

\section{Published: 09 Dec 2013}

\section{References}

1. Safdar N, Dezfulian C, Collard HR, Saint S: Clinical and economic consequences of ventilator-associated pneumonia: a systematic review. Crit Care Med 2005, 33:2184-2193.

2. Muscedere J, Rewa O, McKechnie K, Jiang X, Laporta D, Heyland DK: Subglottic secretion drainage for the prevention of ventilator-associated pneumonia: a systematic review and meta-analysis. Crit Care Med 2011, 39:1985-1991. 
3. Kelley SD: Number needed to treat for subglottic secretion drainage technology as a ventilator-associated pneumonia prevention strategy. Crit Care 2012, 16:446.

4. Lacherade JC, De Jonghe B, Guezennec P, Debbat K, Hayon J, Monsel A, Fangio P, Appere de Vecchi C, Ramaut C, Outin H, Bastuji-Garin S: Intermittent subglottic secretion drainage and ventilator-associated pneumonia: a multicenter trial. Am J Respir Crit Care Med 2010, 182:910-917.

5. Kalfon P, Mimoz O, Auquier P, Loundou A, Gauzit R, Lepape A, Laurens J, Garrigues B, Pottecher T, Mallédant Y: Development and validation of a questionnaire for quantitative assessment of perceived discomforts in critically ill patients. Intensive Care Med 2010, 36:1751-1758.

\section{$10.1186 / \mathrm{cc} 13149$}

Cite this article as: Loupec et al: Subglottic secretion drainage in prevention of ventilator-associated pneumonia: mind the gap between studies and reality. Critical Care 2013, 17:R286 